\title{
IMUNIDADE DE JURISDIÇÃO E A EFETIVIDADE DOS DIREITOS HUMANOS SOCIAIS
}

\section{IMMUNITY OF JURISDICTION AND THE EFFECTIVENESS OF SOCIAL HUMAN RIGHTS}

\author{
Mariana Teixeira Thomé \\ Advogada. Bacharel em Direito pela Pontifícia Universidade Católica de Goiás - PUC- \\ GO. Pós-graduada em Direito Administrativo e Constitucional pela mesa instituição. \\ E-mail: marianatthome@ hotmail.com
}

Ynes da Silva Felix

Possui graduação em Direito pela Universidade Católica Dom Bosco (1985), mestrado em Direito pela Pontifícia Universidade Católica de São Paulo (1993) e doutorado em Direito pela Pontifícia Universidade Católica de São Paulo (2001). Atualmente é professora titular

da Universidade Federal de Mato Grosso do Sul e Diretora da Faculdade de Direito da

UFMS. Professora permanente do curso de mestrado em Direito da Faculdade de Direito da Universidade Federal de Mato Grosso do Sul, orientando trabalhos na linha de pesquisa Direitos Humanos, Estado e Fronteira. E-mail: ynesfelix @uol.com.br

Recebido em: 20/08/2017

Aprovado em: 13/11/2017

Doi: $10.5585 /$ rdb.v18i7.752

RESUMO: O presente trabalho tem por objetivo estudar a imunidade de jurisdição dos Estados e das Organizações Internacionais de modo a confrontar a sua aplicabilidade com a proteção dos direitos humanos sociais. Para tanto, utilizam-se os métodos indutivo e dialético a fim de se examinar casos práticos e correlacioná-los com o uso da teoria da imunidade de jurisdição e de execução. A problemática abrange o fato de que os atos de guerra cometidos pelos Estados gozam de imunidade absoluta a ponto de mitigarem a proteção dos direitos humanos. No mesmo aspecto tem-se o debate que trata da execução de um Estado estrangeiro em face de outro. Nem sempre a execução é dotada de plena efetividade havendo, portanto, um abrandamento da efetiva proteção aos direitos humanos sociais.

Palavras-chaves: Imunidade de jurisdição. Imunidade de execução. Direitos humanos sociais.

\begin{abstract}
The objective of this study is to study the immunity of the states and international organizations in order to confront their applicability with the protection of social human rights. In order to do so, we used the inductive and dialectical methods to examine practical cases and correlate them with the use of jurisdictional and enforcement immunity theory. The problem includes the fact that acts of war committed by States enjoy absolute immunity to the point of mitigating the protection of human rights. In the same aspect there is the debate that deals with the execution of one foreign state in the face of another. Execution is not always fully effective and, therefore, there is a slowing down of effective protection of social human rights.
\end{abstract}

Keywords: Immunity of jurisdiction. Immunity of execution. Social human rights. 
SUMÁRIO: Introdução; 1. Imunidade de Jurisdição; 1.1 Imunidade de jurisdição absoluta: par in parem non habet judicium/imperium; 1.2 Imunidade de jurisdição relativa; 2 . Imunidade de execução; 3. Imunidade das Organizações Internacionais; 4. Direitos Humanos e Imunidade de Jurisdição; 4.1 Princz vs República Federal da Alemanha (EUA) $-1^{\circ}$ de julho de 1994; 4.2 Prefeitura de Voiotia vs República Federal da Alemanha (Grécia) - 4 de maio de 2000; 4.3 AlAdsani vs Kuwait (Reino Unido) - 21 de novembro de 2001; 4.4 Ferrini vs República Federal da Alemanha (Itália) - 11 de março de 2004; 4.5 Espólio de Kazemi vs República Islâmica do Irã (Canadá) - 10 de outubro de 2014; 5. Direitos Humanos e Imunidade de Execução; 5.1 Genny vs República da Alemanha (Brasil - AC no 9.696) - 12 de outubro de 1990; 5.2 Rosa Marinho Rocha vs Reino da Espanha (Brasil - TST-ROMS - 16100-56.2005.5.10.0000) - 15 de março de 2007; 5.3 Edvaldo de Azevêdo vs Estado da Finlândia (Brasil - TST-ROMS - 3210068.2004.5.10.0000) - 15 de dezembro de 2009; 5.4 Nestor de Aquino vs embaixada dos Estados Unidos da América (Brasil - TST-RXOF e ROMS - 23900-38.2005.5.10.0000) - 23 de abril de 2010; 5.5 Patrícia Gutierrez vs Consulado Geral do Chile em São Paulo (Brasil - TST-RR170700-28.2006.5.02.0063) - 20 de fevereiro de 2013; 6. 6.Efetiva Proteção dos Direitos Humanos Sociais Ante à Imunidade de Jurisdição e à Imunidade de Execução; Conclusão; Referências Bibliográficas.

\section{INTRODUÇÃO}

O exercício da jurisdição configura o direito de o Estado aplicar as suas normas a quem está sujeito à sua soberania. Durante o absolutismo, no entanto, surge uma teoria que prevê a inaplicabilidade da jurisdição de um Estado em relação a atos praticados por outro - cuida-se da imunidade de jurisdição. Essa teoria inspirou-se no absolutismo medieval, quando a imposição da lei aos súditos constituía uma prerrogativa do príncipe (SCHIERA, 1999, p. 3 apud TORRES, 2012, p. 99).

Objetiva-se, no presente trabalho, estudar a imunidade de jurisdição na perspectiva da proteção dos direitos humanos sociais. Para tanto, questiona-se sobre as alternativas para solucionar as situações de conflito entre a imunidade de jurisdição e a proteção dos direitos humanos sociais, bem como sobre os valores a serem protegidos por esses dois institutos.

A primeira parte do trabalho é dedicada ao estudo da imunidade de jurisdição, seu aspecto histórico e características. Após, faz-se uma análise da imunidade de execução e suas características. Posteriormente, adentra-se no estudo da proteção dos direitos humanos sociais no aspecto de sua efetividade ante a situação da imunidade de jurisdição e de execução. Ao fim, compara-se a efetiva proteção dos direitos humanos sociais ante a imunidade de jurisdição e a imunidade de execução.

Buscou-se, por meio de casos concretos relevantes, confrontar a aplicação do instituto da imunidade de jurisdição diante de questões humanas e sociais. O objetivo da análise é apontar uma possível solução quando do conflito entre ambos objetos.

\section{IMUNIDADE DE JURISDIÇÃO}

A jurisdição consiste na função do Estado de aplicar suas normas a quem a elas se sujeitar em situações de conflito. Conforme ensina Theodoro Júnior:

[...] estabeleceu-se a jurisdição como o poder que toca ao Estado, entre as suas atividades soberanas, de formular e fazer atuar praticamente a regra jurídica 
concreta que, por força do direito vigente, disciplina determinada situação jurídica (THEODORO JÚNIOR, 2013, p. 38).

É importante observar que, embora a regra seja a aplicação da jurisdição, há determinadas situações em que se limita seu emprego. É o que se chama de imunidade de jurisdição.

Segundo Bröhmer (1997 apud FERNANDES 2010, p. 142) “a imunidade de jurisdição configura um conjunto de regras negativas que estabelecem quando uma corte não pode julgar um caso".

A imunidade de jurisdição é norma do direito internacional que prevê que os Estados são soberanos e possuem tratamento igualitário no plano internacional. Ela tem por fundamento a proteção das pessoas naturais e jurídicas que atuam nas relações internacionais, necessitando de uma defesa maior para que exerçam suas funções sem que haja constrangimentos de qualquer espécie. Tratam dessa matéria as convenções de Viena de 1961 e de 1963.

A Convenção de Viena de 1961 estabelece imunidade de jurisdição aos agentes diplomáticos nas ordens penal, civil e administrativa, salvo quando o interesse defendido civil ou administrativamente for privado. A Convenção de Viena de 1963, por sua vez, estabelece imunidade de jurisdição aos agentes consulares - possuindo um rol menor de imunidades, já que essas abrangem apenas atos diretamente relacionados com o exercício da função de cônsul.

A imunidade de jurisdição configura, de certa forma, uma limitação direta da soberania estatal, haja vista que um Estado estará privado de exercer sua jurisdição sobre determinado ente.

\subsection{Imunidade de jurisdição absoluta: par in parem non habet judicium/imperium}

A imunidade absoluta coaduna com a época em que surgiu: o absolutismo. Durante a maior parte da história, vigorou a teoria da imunidade absoluta dos Estados. Essa pugnava pela impossibilidade de um Estado julgar o outro, salvo com o seu consentimento.

A teoria fundamentava-se na soberania, independência e igualdade jurídica entre os Estados e se baseava no princípio par in parem non habet judicium/imperium, que significa, essencialmente, que "iguais não podem julgar iguais" (PORTELA, 2014, p. 194).

\subsection{Imunidade de jurisdição relativa}

No final do século XIX e meados do século XX, fortaleceu-se a teoria de que os Estados poderiam ser responsabilizados pelos seus atos em outros Estados. Trata-se da teoria da imunidade relativa, que se fundamenta na distinção entre os atos de império e os atos de gestão (PORTELA, 2014, p. 195).

Os atos de império (jure imperium) consistem nos atos em que o Estado pratica no exercício de sua prerrogativa soberana, razão pela qual gozam de imunidade de jurisdição. São os atos que se caracterizam pelo poder de coerção típica do poder de império (CARVALHO FILHO, 2008, p. 124). Como exemplos têm-se: os atos de guerra, atos de concessão ou de denegação de visto, atos de admissão de estrangeiro ao território de um Estado e atos que configurem impedimento de ingresso ou deportação (PORTELA, 2014, p. 196).

Os atos de gestão (jure gestionis), por sua vez, são aqueles em que o ente estatal é equiparado a um particular - não há, portanto, imunidade de jurisdição. São exemplos desses atos: a aquisição de bens móveis e imóveis, atos de natureza comercial, atos relacionados à responsabilidade civil e atos que envolvem questões trabalhistas.

Dessa forma, observa-se que a imunidade absoluta apenas sofreu uma relativização, haja vista que, em se tratando de atos de império há a total imunidade de jurisdição. É importante ressaltar que há autores que não concordam com essa distinção, na medida em que deve haver 
indenização quando ocorre um dano. Esse é o posicionamento de Eneas Bazzo Torres (2002, p. 272 apud VILELA):

Na conformidade deste critério, não importa se o ato é de gestão ou se o ato é de império; se houve a prática de um dano, que esse prejuízo seja indenizado. Penso até que, se não for dessa maneira, não estará sendo respeitado o velho princípio do par in parem non habet imperium. Ora, na medida em que fique dispensado de indenizar, estar-se-á concedendo ao Estado acreditante um privilégio em relação ao Estado acreditado. E, neste caso, termina por ser quebrada a igualdade (TORRES, 2002, p. 272 apud VILELA).

Até a década de 80, no Brasil, prevalecia o entendimento de que a imunidade de jurisdição do Estado estrangeiro era absoluta. Somente em 1989, por meio do julgamento pelo STF da ação cível no 9.696 - Genny de Oliveira vs República Federal da Alemanha - admitiu-se não haver imunidade de jurisdição do Estado estrangeiro em matéria trabalhista julgada após a Constituição de 1988, pela Justiça do Trabalho. Os atos de império, porém, continuaram sujeitos à imunidade de jurisdição.

Esse caso dizia respeito a uma reclamação trabalhista ajuizada na Justiça do Trabalho por Genny de Oliveira em face do Estado alemão. A autora pleiteava o reconhecimento de direitos trabalhistas em favor de seu falecido marido. A Alemanha arguiu sua imunidade à jurisdição, no entanto, essa foi rejeitada com fundamento na doutrina que despertava em âmbito nacional: a da relativização da imunidade com base na Convenção de Viena sobre Relações Consulares de 1963. Assim, os atos de gestão não gozavam de imunidade. Até a época, não havia, na jurisprudência nacional, precedente nesse sentido.

Atualmente, a jurisprudência do TST também coaduna com o fato de que os atos do ente estatal estrangeiro vinculados às relações trabalhistas são atos de gestão e não gozam da imunidade de jurisdição conforme se pode verificar nos acórdãos proferidos nos seguintes processos: $\quad$ RO-188-04.2014.5.10.0000, AIRR-7840-04.1998.5.10.0010, AIRR-784004.1998.5.10.0010, ED-AIRR-142400-61.2008.5.02.0071.

É importante ressaltar que, conforme disposto nos julgados citados acima, os atos de gestão de Estados estrangeiros sujeitos à jurisdição brasileira, dizem respeito a matérias trabalhistas.

Em relação ao processo de submissão dos atos de império à jurisdição de um Estado estrangeiro, tem-se que, no caso a ser apreciado, o juiz responsável deve citar o Estado réu para que exerça o direito de escolha: ou o ente estatal exerce o direito à imunidade jurisdicional ou ele se submete, voluntariamente, à jurisdição brasileira, renunciando, assim, a sua imunidade. É nesse sentido que o STJ decidiu que a ação de uma vítima do nazismo contra a Alemanha não seria processada pela justiça brasileira. No referido julgado, a Alemanha externou a sua intenção de não abrir mão da imunidade de jurisdição, inviabilizando o pedido de indenização pleiteado pela requerente ${ }^{1}$.

\footnotetext{
${ }^{1}$ RO 64 - 2008/0003366-4: DIREITO PROCESSUAL E DIREITO INTERNACIONAL. PROPOSITURA, POR FRANCÊS NATURALIZADO BRASILEIRO, DE AÇÃO EM FACE DA REPÚBLICA FEDERAL DA ALEMANHA VISANDO A RECEBER INDENIZAÇÃO PELOS DANOS SOFRIDOS POR ELE E POR SUA FAMÍLIA, DE ETNIA JUDAICA, DURANTE A OCUPAÇÃO DO TERRITÓRIO FRANCES NA A SEGUNDA GUERRA MUNDIAL. SENTENÇA DO JUÍZO DE PRIMEIRO GRAU QUE EXTINGUIRA O PROCESSO POR SER, A AUTORIDADE JUDICIÁRIA BRASILEIRA, INTERNACIONALMENTE INCOMPETENTE PARA O JULGAMENTO DA CAUSA. REFORMA DA SENTENÇA RECORRIDA.
}

Revista de Direito Brasileira | São Paulo, SP | v. 18 | n. 7 | p. 173 - 190 | Set./Dez. 2017 
A jurisprudência do $\mathrm{STJ}^{2}$ entende que o silêncio do Estado réu na manifestação da escolha da imunidade de jurisdição não implica na renúncia da imunidade (PORTELA, 2014, p. 198 e 199).

É interessante observar a lição de Cançado Trindade (1997, p. 442 apud GUERRA, 2011, p. 345) em relação à responsabilidade do Estado pelas obrigações por ele assumidas. Essas vinculam não apenas o governo, bem como os poderes Executivo, Legislativo e Judiciário. Nesse aspecto tem-se que:

Ao Poder Executivo incumbe tomar todas as medidas - administrativas e outras - a seu alcance para dar fiel cumprimento àquelas obrigações. A responsabilidade internacional pelas violações aos direitos humanos sobrevive aos Governos, e se transfere a Governos sucessivos, precisamente por se tratar de responsabilidade do estado. Ao Poder Legislativo incumbe tomar todas as medidas dentro de seu âmbito de competência, seja para regulamentar os tratados de direitos humanos de modo a dar-lhes eficácia no plano do direito interno, seja para harmonizar este último com o disposto naqueles tratados. $\mathrm{E}$ ao Poder Judiciário incumbe aplicar efetivamente as normas de tais tratados no plano do direito interno, e assegurar que sejam respeitadas. Isso significa que o Judiciário nacional tem o dever de prover recursos internos eficazes contra violações tanto dos direitos consignados na Constituição como dos direitos consagrados nos tratados de direitos humanos que vinculam o país em questão, ainda mais quando a própria Constituição nacional assim expressamente o determina. O descumprimento das normas convencionais engaja de imediato a responsabilidade internacional do estado, por ato ou omissão, seja do Poder

${ }^{2}$ Ag. 1.118.724-RS: INDENIZAÇÃO. TURISTA. DEPORTAÇÃO. O agravante, em viagem de turismo à Nova Zelândia, munido de passagens aéreas de ida e de volta, além do visto de entrada, ao desembarcar, foi posto em uma sala de interrogatórios, obrigado a assinar declaração sem compreender seu conteúdo, pois não é fluente em inglês e, por fim, teve de retornar ao Brasil com os documentos retidos pelo comandante do avião. Diante desses acontecimentos, propôs ação de reparação por danos morais e materiais em desfavor daquele país, mas o juiz considerou inepta a inicial com base nos arts. 295, I, seu parágrafo único, III, e 267, I, ambos do CPC, entendendo ainda ser lícita a recusa do país em receber o viajante, visto não existir qualquer norma internacional que obrigue os países a aceitar, em seu território, estrangeiros visitantes. Então, o recorrente interpôs recurso ordinário (art. 539, II, b, parágrafo único, do CPC) ao qual a Turma deu provimento (RO n. 70-RS, DJe 23/6/2008),remetendo ofício ao Ministério das Relações Exteriores (MRE). Esse órgão noticiou, em ofício enviado à Presidência da Terceira Turma, que a Embaixada daquele país, na nota verbal n. 22/2008, na qual informa ter tomado conhecimento do julgamento do recurso ordinário, bem como que "não aceita qualquer jurisdição dos tribunais brasileiros sobre a Nova Zelândia em assuntos como imigração e o direito básico de qualquer Estado decidir quem pode entrar em seu território". Dada vista à parte autora do ofício do MRE e da anexa nota verbal da Embaixada da Nova Zelândia, em ato contínuo, foram os autos conclusos ao juiz de origem, que indeferiu o requerimento no qual o agravante insistia na necessidade de citação daquele país, o que resultou no agravo de instrumento em questão. Quanto a isso, observa a Min. Relatora que, antes, havia divergência neste Superior Tribunal quanto a ser ou não citação a comunicação ao Estado estrangeiro para manifestar sua opção pelo direito à imunidade jurisdicional ou pela renúncia a essa prerrogativa. Segundo a Min. Relatora, consolidou-se o entendimento de que a comunicação ao Estado estrangeiro não é a citação prevista no art. 213 do CPC, nem mesmo de intimação se trata, porquanto nenhum ônus decorre ao ente estrangeiro. Por outro lado, a jurisprudência já se havia firmado quanto a se ter como possivelmente competente a Justiça brasileira para a ação de indenização em virtude de danos morais e materiais alegadamente causados a cidadãos nacionais por país estrangeiro em seu território e decorrentes de ato de império, desde que o réu voluntariamente renunciasse à imunidade de jurisdição que lhe é reconhecida. Isso posto, ressalta ainda a Min. Relatora que a manifestação do Estado agravado de que não renunciaria à sua imunidade jurisdicional veio aos autos pela comunicação do MRE e que, na hipótese dos autos, não se trata de ação judicial decorrente dos chamados atos de gestão, mas estaria de acordo com os procedimentos citatórios de um Estado estrangeiro. Dessa forma, no seu entender, a manifestação cumpriu a contento a exigência de oportunizar ao Estado da Nova Zelândia sua prévia oitiva, porquanto suficiente para que pudesse expressar e reafirmar a sua soberania, como de fato o fez. Por essas razões, a Turma negou provimento ao agravo. Precedentes citados: RO 57-RJ, DJe 14/9/2009; RO 85-RS, DJe 17/8/2009; RO 66-RJ, DJe 19/5/2008, e RO 57-RJ, DJe 14/9/2009. Ag 1.118.724-RS, Rel. Min. Nancy Andrighi, julgado em 16/9/2010.

Revista de Direito Brasileira | São Paulo, SP | v. 18 | n. 7 | p. 173 - 190 |Set./Dez. 2017 
Executivo, seja do Legislativo, seja do Judiciário (TRINDADE 1997, p. 442 apud GUERRA 2011, p. 345).

Atualmente, a imunidade de jurisdição possui como norte regulamentador as Convenções de Viena sobre Relações Diplomáticas de 1961 e sobre Relações Consulares de 1963. Há, também, normas escritas sobre o tema como, por exemplo, a Convenção Europeia sobre a Imunidade de Jurisdição dos Estados de 1972, o Foreing Sovereign Immunity Act de 1976 e o State Immunity Act de 1978 e Immunidad Jurisdiccional de los Estados Extranjeros ante los Tribunales Argentinos. Esses diplomas não permitem a imunidade absoluta de jurisdição, especialmente em questões trabalhistas e em ações indenizatórias fundadas na responsabilidade civil.

A referida Convenção Europeia sobre a Imunidade de Jurisdição dos Estados contém regras comuns relativas à extensão da imunidade de uma parte perante a jurisdição dos tribunais de uma outra parte, conforme está disposto, por exemplo, no artigo 5, parágrafo 2:

\section{Article 5}

1 A Contracting State cannot claim immunity from the jurisdiction of a court of another Contracting State if the proceedings relate to a contract of employment between the State and an individual where the work has to be performed on the territory of the State of the forum.

2 Paragraph 1 shall not apply where:

a the individual is a national of the employing State at the time when the proceedings are brought;

$\mathrm{b}$ at the time when the contract was entered into the individual was neither a national of the State of the forum nor habitually resident in that State; or

$\mathrm{c}$ the parties to the contract have otherwise agreed in writing, unless, in accordance with the law of the State of the forum, the courts of that State have exclusive jurisdiction by reason of the subject-matter (EUROPEAN CONVENTION ON STATE IMMUNITY, 1972).

Essa mesma convenção determina os casos em que uma parte não pode invocar imunidade perante tribunais estrangeiros (artigo 2), fato que ocorre quando ela aceita a jurisdição dos tribunais de outra parte em processos relativos a contratos de trabalho (artigo 5, item 1); a atividades industriais, comerciais ou financeiras (artigo 7, item 1 e artigo 11); a direito de propriedade sobre imóveis (artigo 9) e a reparação de danos físicos ou materiais (artigo 10).

No Brasil, o marco jurídico do tema, conforme abordado, vem sendo regulado pela jurisprudência dos tribunais superiores com fundamento em norma costumeira internacional.

É importante ressaltar que a diferenciação entre atos de gestão e atos de império para fins de aplicação da imunidade de jurisdição apenas se aplica nos processos de conhecimento.

\section{IMUNIDADE DE EXECUÇÃO}

A imunidade de execução é a possiblidade de o Estado estrangeiro estar imune à execução forçada da sentença transitada em julgado obtida na fase de conhecimento. Ahmed Maihou (1990 apud PEDREIRA 1998, p. 231) esclarece que a imunidade de execução visa evitar que um Estado esteja sujeito a medidas de penhora e outras de constrição.

A imunidade de execução, embora seja autônoma em relação à imunidade de jurisdição nada mais é do que uma fase posterior ao processo de conhecimento, quando já afastada a imunidade de jurisdição. Primeiro ingressa-se com um processo de conhecimento a fim de se analisar o direito pleiteado. Após a sentença, tem-se a execução. 
Segundo Torres (2012, p. 105), entretanto, a distinção que se faz entre imunidade de jurisdição e a imunidade de execução é meramente política, sem nenhum suporte jurídico. Isso se deve ao fato de que, independentemente da espécie de imunidade, a questão central é a possiblidade do exercício de jurisdição de um Estado sobre outro.

Parte da doutrina defende a imunidade de execução absoluta, fundamentando-se nas Convenções de Viena sobre Relações Diplomáticas de 1961 e sobre Relações Consulares de 1963. Ambas convenções consagram a inviolabilidade dos bens das missões diplomáticas e consulares (PORTELA, 2014, p. 200).

No STF, há tanto julgados que entendem ser a imunidade de execução absoluta, quanto outros que a relativiza. A relativização ocorre quando há, em território brasileiro, bens não afetos às atividades diplomáticas e consulares.

Cita-se, como exemplo, o entendimento firmado na ação cível originária $n^{0} 709^{3}$, que concluiu pela imunidade de execução absoluta, salvo no caso de expressa renúncia do Estado estrangeiro. Nessa ação, ficou vencido o voto do relator, Ministro Celso de Mello, que defendia ser possível execução contra Estado alienígena, desde que recaia sobre bens que não guardem vinculação específica com a atividade diplomática o consular.

Em se tratando de imunidade de execução, nota-se que a jurisprudência brasileira tem realizado alternativas para promover o cumprimento da sentença estrangeira. Dentre essas alternativas destacam-se a realização de negociações diplomáticas com o Estado estrangeiro; o envio de rogatória para o ente estatal alienígena para que ali se processe a execução e medidas executórias sobre bens não afetos às atividades diplomáticas ou consulares ${ }^{4}$.

É importante também citar, no aspecto de cooperação entre Estados, a novidade trazida pelo Código de Processo Civil de 2015 a respeito da cooperação internacional. Esse capítulo do novo CPC (arts. 26 a 41) trata de elementos processuais com o fim permitir uma tutela jurisdicional mais efetiva no âmbito do direito internacional. Regulamenta-se, por exemplo, a citação, a intimação e a notificação judicial e extrajudicial; a homologação e o cumprimento de decisão; a concessão de medida judicial de urgência e a assistência jurídica internacional.

Salienta-se, em relação à execução fiscal, que o STF entende que há imunidade de execução absoluta do Estado acreditante ${ }^{5}$.

\footnotetext{
${ }^{3}$ Trata-se de Ação Cível Originária proposta pela União, representada pela Caixa Econômica Federal, em desfavor do Consulado Geral da França em São Paulo. Execução judicial contra Estado estrangeiro. Competência originária do Supremo Tribunal Federal (CF, art. 102, I, "e"). Imunidade de jurisdição (imunidade à jurisdição cognitiva) e imunidade de execução (imunidade à jurisdição executiva). O "status quaestionis" na jurisprudência do Supremo Tribunal Federal. Precedentes. Doutrina. Prevalência do entendimento no sentido da impossibilidade jurídica de execução judicial contra estados estrangeiros, exceto na hipótese de expressa renúncia, por eles, a essa prerrogativa de ordem jurídica. Posição pessoal do relator (Ministro Celso de Mello), que entende viável a execução contra estados estrangeiros, desde que os atos de constrição judicial recaiam sobre bens que não guardem vinculação específica com a atividade diplomática e/ou consular. Observância, no caso, pelo relator, do princípio da colegialidade. Julgamento da causa nos termos da jurisprudência predominante no Supremo Tribunal Federal. Processo de execução declarado extinto, sem resolução de mérito.

4 RE-AGR n. 222.368/PE: AGRAVO DE INSTRUMENTO EM RECURSO DE REVISTA PREQUESTIONAMENTO - SÚMULA 297, I, DO TST - IMUNIDADE DE JURISDIÇÃO. Inviável se mostra o prosseguimento do recurso de revista quando a parte indica violação de dispositivos ou de matéria jurídica que não constaram do acórdão regional. No caso, o Agravante suscitou violação dos arts. $8^{\circ}$ da CLT, 126 do CPC e $2^{\circ}$ da CF, sendo que o TRT sobre eles não se manifestou. Ainda que assim não fosse, tem-se que a jurisprudência desta Corte, seguindo na trilha do STF, orienta-se no sentido de que a imunidade de jurisdição não é mais absoluta, tratando-se de imunidade relativa quando o direito em disputa diga respeito a atos de gestão, situação em que o ente estrangeiro se equipara ao particular. Assim, somente é absoluta a imunidade de jurisdição quando se tratar de atos de império praticados pelo Estado estrangeiro, o que não é o caso de reclamação trabalhista, em que a disputa circunscreve-se a interesses de particulares à luz de norma infraconstitucional (CLT). Ademais, a imunidade estaria limitada ao processo de execução, não ao de conhecimento. Agravo de instrumento desprovido.

${ }^{5}$ ACO 740 AgR /SP, ACO 633-AgR, ACO 645-AgR, ACO 522-AgR.
}

Revista de Direito Brasileira | São Paulo, SP | v. 18 | n. 7 | p. 173 - 190 |Set./Dez. 2017 
No âmbito do TST prevalece o entendimento de que a imunidade de execução é relativa a ponto de se proteger apenas os bens do Estado afetos às suas atividades diplomáticas e consulares $^{6}$. Esse entendimento baseia-se no fato de que tanto a Convenção de Viena sobre Relações Diplomáticas (1961) como a Convenção de Viena sobre Relações Consulares (1963), asseguram, em seus artigos, a inviolabilidade dos bens que estejam afetos à missão diplomática e consular.

Dessa forma, não se trata de uma imunidade executória, mas sim de uma proibição de executar os bens que estejam localizados no âmbito da jurisdição brasileira e que estejam afetados à Missão.

É importante destacar as formas que o Estado estrangeiro possui para saldar o débito no Estado acreditado. Conforme disciplinado por Henrique Portela (2014, p. 201), o débito do ente estatal estrangeiro derrotado em processo judicial pode ser quitado por meio de: execução de bens não afetos aos serviços diplomáticos e consulares do Estado estrangeiro; pagamento voluntário; negociações conduzidas pelo Ministério das Relações Exteriores do Brasil (solicitando-se o pagamento pelas vias diplomáticas); expedição de carta rogatória ao Estado estrangeiro; e renúncia à imunidade de execução pelo Estado alienígena.

\section{IMUNIDADE DAS ORGANIZAÇÕES INTERNACIONAIS}

As regras relativas às imunidades das organizações internacionais estão previstas, normalmente, em seus atos constitutivos ou em tratados específicos. Assim, a fonte normativa para tanto é o direito convencional (PORTELA, 2014, p. 202).

Os principais acordos que vigoram sobre o tema no Brasil são: a Convenção sobre Privilégios e Imunidades das Nações Unidas de 1946, a Convenção sobre Privilégios e Imunidades das Agências Especializadas das Nações Unidas de 1947 e o Acordo sobre Privilégios e Imunidades da Organização dos Estados Americanos de 1949.

Salienta-se que há países em que as imunidades das organizações internacionais estão previstas em normas internas como, por exemplo, o caso dos Estados Unidos da América (PORTELA, 2014, p. 203).

O Brasil não possui entendimento consolidado em relação à imunidade das organizações internacionais, dividindo-se, assim, em duas posições: a de que a imunidade dos organismos internacionais é absoluta e a de que essa imunidade é relativa, não prevalecendo, nesse caso, quando se trata de atos de gestão.

No TST, havia decisões ${ }^{7}$ que pugnavam tanto pela imunidade relativa quanto pela imunidade absoluta na seara trabalhista. $\mathrm{O}$ entendimento em favor da imunidade relativa distingue a existência de atos de gestão e atos de império para a aplicação da jurisdição, enquanto que o outro posicionamento se vale do fato de que as imunidades das organizações internacionais

6 RO-188-04.2014.5.10.0000: ESTADO ESTRANGEIRO. IMUNIDADE DE JURISDIÇÃO. CARÁTER RELATIVO. PENHORA DE IMÓVEL. PROVA DE AFETAÇÃO À ATIVIDADE DIPLOMÁTICA OU CONSULAR NÃO PRODUZIDA. IMPOSSIBILIDADE DE ULTIMAÇÃO DOS ATOS DE EXPROPRIAÇÃO. Ao entendimento de que a imunidade de jurisdição reconhecida aos Estados estrangeiros, em execução de sentença, possui caráter relativo, concluiu a SBDI-II que somente estarão imunes à constrição judicial os bens comprovadamente vinculados ao exercício das atividades de representação consular e diplomática. Sob esse entendimento, a Subseção, à unanimidade, conheceu do recurso ordinário e, no mérito, deu-lhe provimento para conceder parcialmente a segurança, determinando que os atos de expropriação do imóvel penhorado - em razão da presunção de não afetação à atividade de representação diplomática ou consular, extraída do silêncio do ente estrangeiro executado, regularmente intimado - sejam interrompidos, somente podendo prosseguir se demonstrado, efetivamente, que o bem não se encontra afetado à missão diplomática ou consular. TST-RO-188-04.2014.5.10.0000, SBDI-II, rel. Min. Douglas Alencar Rodrigues, 29.9.2015.

${ }^{7}$ E-ED-RR - 45700-35.2004.5.10.0008, ROAR-56/2003-000-23.00.0 e E-RR-189280/1995.

Revista de Direito Brasileira | São Paulo, SP | v. 18 | n. 7 | p. 173 - 190 | Set./Dez. 2017 
fundamentam-se em tratados específicos próprios do organismo internacional - assim, os vínculos laborais estariam fora do alcance da CLT.

Com o objetivo de encerrar esse dilema o TST editou, em 2012, a OJ da SDI-1 que discorre sobre a imunidade de jurisdição absoluta aplicada aos organismos internacionais:

OJ-SDI-1 416. IMUNIDADE DE JURISDIÇÃO. ORGANIZAÇÃO OU ORGANISMO INTERNACIONAL. (DEJT divulgado em 14, 15 e 16.02.2012) (mantida conforme julgamento do processo TST-E-RR-6160041.2003.5.23.0005 pelo Tribunal Pleno em 23.05.2016)

As organizações ou organismos internacionais gozam de imunidade absoluta de jurisdição quando amparados por norma internacional incorporada ao ordenamento jurídico brasileiro, não se lhes aplicando a regra do Direito Consuetudinário relativa à natureza dos atos praticados. Excepcionalmente, prevalecerá a jurisdição brasileira na hipótese de renúncia expressa à cláusula de imunidade jurisdicional (ORIENTAÇÃO JURISPRUDENCIAL No 416 DA SEÇÃO DE DISSÍDIOS INDIVIDUA̧IS 1).

Como se percebe, o TST entendeu que as organizações internacionais são dotadas de imunidade absoluta quando a norma internacional que prevê a imunidade é incorporada ao ordenamento jurídico brasileiro. A imunidade, no entanto, passa a ser relativa, apenas quando há renúncia do organismo à cláusula de imunidade de jurisdição.

O STF também entende que a imunidade de jurisdição das organizações internacionais é absoluta. Esse entendimento foi afirmado nos julgamentos do RE 578.543 e do RE 597.368, que reconheceram a imunidade dessas organizações e entenderam que o art. 114 da Constituição Federal não afasta a imunidade de jurisdição prevista nos tratados internacionais.

Dessa forma, percebe-se que as organizações internacionais gozam de imunidade de jurisdição absoluta com fundamento nos tratados internacionais. No caso de haver um litígio entre o organismo internacional e um empregado, seu o conflito deve ser solucionado por meio de mecanismos indicados pela própria entidade como, por exemplo, foros arbitrais, mecanismos de conciliação ou tribunais administrativos da própria organização (PORTELA, 2014, p. 205).

\section{DIREITOS HUMANOS E IMUNIDADE DE JURISDIÇÃO}

Após apresentação dos conceitos e definições sobre jurisdição, imunidade de jurisdição e imunidade de execução, inicia-se uma abordagem sobre a aplicabilidade desses nas situações em que se depara com os direitos humanos sociais. Nesse capítulo adentra-se na seara relativa à proteção dos direitos humanos sociais quando confrontados com a imunidade de execução dos Estados.

Os direitos humanos estão atrelados à dignidade da pessoa humana no sentido de que todos são iguais e não devem sofrer discriminações de qualquer cunho. A dignidade, uma vez inerente ao ser humano deve ser respeitada por todos (PADILHA, BERTONCINI, 2016, p. 106). Nesse aspecto cita-se o conceito de direitos humanos de Louis Henkin (1979, p. 1-3 apud PIOVESAN 2013, p. 65):

Direitos humanos constituem um termo de uso comum, mas não categoricamente definido. Esses direitos são concebidos de forma a incluir aquelas 'reivindicações morais e políticas que, no consenso contemporâneo, todo ser humano tem ou deve ter perante a sua sociedade ou governo', reivindicações estas reconhecidas como 'de direito' e não apenas por amor, graça ou caridade (HENKIN 1979, p. 1-3 apud PIOVESAN 2013, p. 65). 
Em relação à positivação das normas de direitos humanos, Portela (2014, p. 224), afirma que a doutrina majoritária entende que, em razão da função protetiva e garantista desses direitos, eles não se fundamentam na positivação de suas normas. Ressalta-se nesse ponto, o caráter das recomendações da OIT.

No Direito Internacional, são fontes dos direitos humanos: os tratados, os costumes, a jurisprudência dos foros internacionais, a doutrina, as resoluções das organizações internacionais e o soft law, que normalmente consagram a maior parte das normas da matéria (PORTELA, 2014, p. 823). Ademais, as normas de direitos humanos sociais são de tamanha relevância que compreendem parte do jus cogens, dos princípios gerais do Direito e dos princípios gerais do Direito Internacional.

Abaixo listam-se os casos mais relevantes em se tratando da proteção dos direitos humanos civis e políticos diante da imunidade de jurisdição dos Estados.

\subsection{Princz vs República Federal da Alemanha (EUA) - $1^{\circ}$ de julho de 1994}

Trata-se do caso do cidadão americano Hugo Princz - que processou a república da Alemanha, nos Estados Unidos, em razão de ter sido submetido ao holocausto. Ele buscava reparações pelos danos e injúrias sofridas bem como pelo fato de ter trabalhado em condições de trabalho escravo quando prisioneiro nos campos nazistas.

O autor baseou seu pedido de indenização no estatuto americano sobre o tema, o Foreign Sovereign Immunities Act de 1976. Ele alegou que a mera prática desses atos vis pela Alemanha implicava na renúncia tácita do país à sua imunidade.

A corte americana, ao analisar o processo, não acolheu a tese de Princz, fundamentando no fato de que é dever do Estado estrangeiro, em cada caso, estabelecer a sua imunidade, situação em que não se aplica, de nenhuma forma, as exceções previstas no Foreign Sovereign Immunities Act de 1976.

\subsection{Prefeitura de Voiotia vs República Federal da Alemanha (Grécia) - 4 de maio de 2000}

Durante a segunda guerra mundial, as forças alemãs massacraram mais de 300 habitantes na vila de Distomo, na Grécia. Décadas depois, os parentes das vítimas ingressaram na corte grega pleiteando indenização do Estado alemão.

A corte, em uma decisão inédita, considerou a Alemanha responsável pelos atos de guerra condenando-a a indenizar os autores da ação. O Estado alemão, no entanto, apelou à uma Corte Especial grega, formada especialmente para o caso, que reformou a decisão.

A reforma da decisão fundamentou-se no fato de que a exceção à regra da imunidade estatal contida na Convenção Europeia sobre a Imunidade de Jurisdição dos Estados não inclui os delitos resultantes de conflitos armados.

Nesse aspecto, é importante observar o fato de que o termo "conflitos armados" é genérico e bastante amplo, não se referindo, apenas a atos relativos à guerra, mas sim a todos os tipos de conflitos armados, em todas as circunstâncias.

\subsection{Al-Adsani vs Kuwait (Reino Unido) - 21 de novembro de 2001}

Al-Adsani é um piloto que possui nacionalidade britânica e kuwaitiana. Em meados dos anos 90, ele se alista no Kuwait e acaba tendo posse de vídeos íntimos do sheik Jaber Al-Sabah Al-Saud Al-Sabah.

Os vídeos acabam tendo circulação geral, razão pela qual o sheik imputa tal ato a AlAdsani. Assim o sheik o rapta e o submete a tortura. Dentre as práticas de tortura destacam-se o espancamento, mergulho de sua em uma piscina contendo cadáveres e o confinamento em uma 
sala pequena com colchões em chamas (BRANT; BIAZATTI). Em decorrência dos atos de tortura, Al-Adsani teve grandes traumas psicológicos e $25 \%$ do seu corpo queimado.

Ao retornar para o Reino Unido, o piloto move uma ação cível de reparação de danos contra o Kuwait. A corte inglesa, no entanto, arquiva o processo com fundamento no State Immunity Act de 1978, que assegura imunidade jurisdicional a Estados estrangeiros em processos cíveis perante o judiciário inglês. Diferentemente, esse diploma legal não aplicaria a imunidade de jurisdição em casos que envolvam morte ou danos pessoais ocorridos em território britânico.

Inconformado, Al-Adsani recorre à Corte Europeia de Direitos Humanos. A corte decide pela imunidade de jurisdição do Kuwait, com fundamento no fato de que o direito de acesso à justiça não é absoluto, podendo sofrer limitações como a presente no State Immunity Act de 1978. Para o órgão a imunidade de jurisdição dos Estados busca um objetivo legítimo que consiste no respeito ao Direito Internacional promovendo-se, assim, a cortesia e as boas relações entre os Estados.

\subsection{Ferrini vs República Federal da Alemanha (Itália) - 11 de março de 2004}

Luigi Ferrini é um cidadão italiano que foi capturado e deportado para a Alemanha pelas tropas nazistas em agosto de 1944. Lá foi submetido a trabalhos forçados nas fábricas alemãs e, posteriormente, transferido para um campo de concentração, onde ficou até abril de 1945.

Em setembro de 1998, Ferrini ingressa com uma ação contra a Alemanha no tribunal de Arezzo, na Itália, pleiteando indenização pelos danos físicos e psicológicos sofridos na época em que estava detido.

A Alemanha alega imunidade de jurisdição pelos seus atos com fundamento nas normas consuetudinárias do Direito Internacional. O tribunal de Arezzo rejeitou a ação com fundamento de que os atos praticados pelo Estado alemão eram atos de império, portanto, sujeitos à imunidade de jurisdição.

Ferrini então recorre à corte de Florença que confirma a decisão do tribunal de Arezzo. Assim, ele recorre à Suprema Corte que reforma, em 2004, a decisão anterior e nega a imunidade de jurisdição da Alemanha baseada no fato de que, embora o direito consuetudinário prescreva a imunidade de jurisdição de um Estado estrangeiro, ela não pode abarcar atos que constituem crimes internacionais.

Para a corte, violações de direitos humanos fundamentais confrontam com valores universais protegidos por normas de jus cogens, que estão no topo da hierarquia de normas na ordem jurídica internacional. Dessa forma, a corte entendeu que as normas jus cogens de proteção precedem as leis conflitantes, inclusive a imunidade estatal.

Esse julgamento serviu de base para que centenas de reivindicações de danos contra a Alemanha fossem postulados em tribunais italianos.

Em 23 de dezembro de 2008, a Alemanha recorre contra a decisão da corte italiana na Corte Internacional de Justiça alegando que o judiciário italiano não respeitou a imunidade de jurisdição alemã enquanto Estado soberano.

No dia 3 de fevereiro de 2012, a Corte Internacional de Justiça decidiu que a República da Itália violou a obrigação de respeito à imunidade de jurisdição do Estado alemão, visto que a Itália permitiu a instauração de várias ações cíveis fundadas na violação de normas humanitárias cometidas pelo Reich alemão entre 1943 e 1945.

\subsection{Espólio de Kazemi vs República Islâmica do Irã (Canadá) - 10 de outubro de 2014}

Kazemi era uma cidadã canadense que visitou o Irã em 2003 com fins profissionais. Lá ela foi sequestrada, detida, agredida fisicamente, torturada e abusada sexualmente, falecendo em 
razão de lesões cerebrais decorrentes desses atos. Seu filho, Hashemi, solicitou que o seu corpo fosse enviado até o Canadá. O enterro, entretanto, ocorreu no Irã.

O governo iraniano então elaborou um relatório que ligava membros do judiciário à tortura de Kazemi. No entanto, apenas um indivíduo foi julgado e absolvido em um julgamento marcado por falta de transparência.

Assim, em 2006, o espólio e Hashemi ingressaram com uma ação no Quebec de responsabilidade civil contra o Estado do Irã, seu Chefe de Estado e algumas outras autoridades. Postulou-se indenização em razão dos traumas psicológicos, físicos e emocionais sofridos por Kazemi e pelos danos psicológicos e emocionais sofridos por Hashemi em razão da perda de sua mãe. Também foi postulado, conforme permite o direito canadense, que a condenação fosse ampliada de modo a se tornar punitiva e exemplar.

O Irã e demais demandados apresentaram uma moção na Quebec Superior Court of Justice, solicitando o arquivamento do processo com fundamento no princípio da imunidade de jurisdição do Estado, previsto no artigo $3^{\circ}$ do Canada State Immunity Act (SIA).

Nessa corte, houve a rejeição da ação, em relação ao pedido do espólio, com fundamento no fato de que as agressões e a morte ocorreram em Teerã, não em território canadense, conforme exige o artigo $6^{\circ}$ do SIA. Já o pedido do Sr. Hashemi foi deferido, afastando a imunidade de jurisdição do Irã, haja vista que os danos sofridos por Kazemi repercutiram na integridade pessoal do seu filho no Canadá.

Os requeridos e os requerentes apelaram à Quebec Court of Appeal. Nessa corte, manteve-se a decisão proferida em relação ao espólio e alterou-se a decisão proferida em relação a Hashemi, decidindo, portanto a favor da tese da imunidade de jurisdição do Estado.

Hashemi recorreu então à Supreme Court, corte final de apelação, pugnando pela incompatibilidade da SIA com previsões constitucionais e quase constitucionais. Essa corte, posicionou-se, no sentido de que atrelar completude à SIA - de forma que os atos de tortura não configuram exceção à sua aplicabilidade.

\section{DIREITOS HUMANOS E IMUNIDADE DE EXECUÇÃO}

Nesse capítulo adentra-se na seara relativa à proteção dos direitos humanos sociais quando confrontados com a imunidade de execução dos Estados.

Os direitos humanos abrangem os direitos civis, políticos, econômicos, sociais e culturais. O objetivo do presente artigo é tratar acerca dos direitos humanos em geral bem como em seu contexto social, especificamente, quando se trata das relações de trabalho. Moraes (2012, p. 205) define os direitos sociais como:

Direitos sociais são direitos fundamentais do homem, caracterizando-se como verdadeiras liberdades positivas, de observância obrigatória em um Estado Social de Direito, tendo por finalidade a melhoria de condições de vida aos hipossuficientes, visando à concretização da igualdade social (MORAES 2012, p. 205).

Nesse aspecto, priorizou-se julgados relevantes da corte do Brasil, em razão de, no âmbito internacional, prevalecerem questões relativas à imunidade de jurisdição vinculadas, majoritariamente, a atos de guerra.

\subsection{Genny vs República da Alemanha (Brasil - AC no 9.696) - 12 de outubro de 1990}

A autora pleiteava o reconhecimento dos direitos trabalhistas em favor de seu falecido marido. A Alemanha arguiu sua imunidade à jurisdição. O juízo federal de primeiro grau 
reconheceu a imunidade de jurisdição. Após, houve vários recursos de modo que a questão chegou até o STF.

A Suprema Corte, em Recurso Extraordinário entendeu que não há imunidade de jurisdição para o Estado estrangeiro em causa de natureza trabalhista, já que as questões trabalhistas estão afetas aos atos de gestão, não gozando de imunidade.

O STF também decidiu que, em razão de a ação ter sido proposta antes do advento da Constituição de 1988, a competência para julgá-la estava afeta à Justiça Federal, em face do disposto no parágrafo 10 do art. 27 do A.D.C.T da Constituição Federal de 1988, c/c art. 125, II, da $E C n^{\circ} 1 / 69$.

\subsection{Rosa Marinho Rocha vs Reino da Espanha (Brasil - TST-ROMS - 16100- 56.2005.5.10.0000) - 15 de março de 2007}

Rosa Marinho Rocha ingressou com uma reclamação trabalhista no TRT $10^{\mathrm{a}}$ Região em face do Reino da Espanha. O Estado foi condenado em decisão de primeiro grau. Diante de uma possível penhora em sede de execução definitiva, a Espanha recorreu alegando que gozava de imunidade de jurisdição absoluta no processo de execução. Em sua defesa, o país alegou que tanto os bens afetos às atividades diplomáticas quanto os não afetos seriam impenhoráveis, haja vista se tratarem de bens públicos.

No TST, haja vista ter sido impetrado um mandado de segurança preventivo, o tribunal decidiu que a penhora, quando realizada, deve ocorrer apenas sobre os bens não afetos às atividades diplomáticas, conforme o disposto no art. $3^{\circ}$ da Convenção de Viena e na jurisprudência pacífica do Supremo Tribunal Federal ${ }^{8}$.

\subsection{Edvaldo de Azevêdo vs Estado da Finlândia (Brasil - TST-ROMS - 32100- 68.2004.5.10.0000) - 15 de dezembro de 2009}

Edvaldo de Azevêdo ingressou com ação trabalhista contra o Estado finlandês no TRT $10^{a}$ Região. Em primeiro grau, o país foi condenado de forma que o teve, em fase de execução definitiva, penhorado numerário existente em sua conta bancária. Contra esse ato, o Estado impetrou mandado de segurança alegando ofensa ao seu direito líquido e certo da imunidade de execução, conforme previsto nas Convenções de Viena de 1961 e 1963.

O TRT concedeu a segurança desconstituindo a penhora realizada, determinando a restituição dos valores penhorados ao impetrante, haja vista que os valores creditados na conta bancária do Estado estrangeiro são abrangidos pela imunidade de execução.

Azevêdo recorreu da decisão de segundo grau a fim de o numerário existente na conta bancária da Finlândia fosse penhorado. O TST decidiu que, em razão de impossibilidade de se distinguir se os créditos possuíam natureza comercial ou estavam destinados exclusivamente à manutenção e administração da embaixada, presume-se que o montante é afeto à missão diplomática, não passível de penhora.

\footnotetext{
8 AI-AgR 139671/DF: AGRAVO DE INSTRUMENTO - ESTADO ESTRANGEIRO - RECLAMAÇÃO TRABALHISTA AJUIZADA POR EMPREGADOS DE EMBAIXADA - IMUNIDADE DE JURISDIÇÃO CARÁTER RELATIVO - RECONHECIMENTO DA JURISDIÇÃO DOMÉSTICA DOS JUÍZES E TRIBUNAIS BRASILEIROS - AGRAVO IMPROVIDO.
} 


\subsection{Nestor de Aquino vs embaixada dos Estados Unidos da América (Brasil - TST-RXOF e ROMS - 23900-38.2005.5.10.0000) - 23 de abril de 2010}

Nestor Souza de Aquino ingressou com uma ação no TRT $10^{\mathrm{a}}$ Região em face da embaixada dos Estados Unidos. No primeiro grau, a instituição foi condenada, de forma que determinou-se penhora de numerário existente em sua conta-bancária.

O Estado impetrou mandado de segurança alegando ofensa à imunidade de execução. No TST, o tribunal liberou os eventuais valores penhorados em razão da impossibilidade de se distinguir se os valores sob penhora possuíam natureza meramente comercial ou se estavam afetos às atividades da embaixada.

\subsection{Patrícia Gutierrez vs Consulado Geral do Chile em São Paulo (Brasil - TST-RR- 170700-28.2006.5.02.0063) - 20 de fevereiro de 2013}

Patrícia Gutierrez ingressou com reclamação trabalhista no TRT da $2^{\mathrm{a}}$ Região, postulando as diferenças salariais decorrentes da redução salarial em razão da redução da taxa de câmbio.

Em recurso, o tribunal deu parcial provimento ao recurso interposto pelo Consulado do Chile, declarando a imunidade parcial da execução. Inconformado, o reclamado interpôs recurso de revista tendo o Tribunal Superior do Trabalho decidido pela improcedência da execução, haja vista a impossibilidade de se distinguir se os valores depositados em conta corrente do Estado estrangeiro estão afetados às funções precípuas da missão diplomática ou se são destinados a meros atos comerciais.

\section{EFETIVA PROTEÇÃO DOS DIREITOS HUMANOS SOCIAIS ANTE À IMUNIDADE DE JURISDIÇÃO E À IMUNIDADE DE EXECUÇÃO}

Por meio dos julgados colacionados, percebe-se que a proteção aos direitos humanos não ocorre de forma plena.

No que tange à imunidade de jurisdição, nota-se que, ainda que a maioria dos atos praticados contra a proteção dos direitos humanos civis e políticos tenha sido cometida durante período de guerra, prevalece o entendimento de que há imunidade absoluta em relação a tais atos por se tratarem de atos de império.

Ademais, embora haja diplomas que discorram sobre a exceção da aplicação da imunidade de jurisdição - como, por exemplo, o State Immunity Act de 1978 - nenhum deles foi efetivo em proteger os direitos humanos civis quando confrontados com atos de guerra.

A maioria dos diplomas que discorre sobre a exceção da aplicação da imunidade de jurisdição afirma que a imunidade não é aplicada quando o ato cometido pelo Estado acreditante é praticado dentro do território do Estado acreditado. Em razão desse entendimento, percebe-se que os direitos humanos foram desprotegidos nos casos Al-Adsani vs Kuwait e Espólio de Kazemi vs República Islâmica do Irã.

Em ambos casos, como o ato de ofensa à dignidade humana foi praticado em um Estado alheio ao Estado acreditado, não se aplicou o diploma que permite a inaplicabilidade da imunidade jurisdicional.

No caso relativo à prefeitura de Voiotia vs República Federal da Alemanha, a primeira instância de julgamento considerou a Alemanha responsável pelos atos de guerra, afastando a sua imunidade de jurisdição. Esse fato, no entanto, não foi sustentado nas cortes superiores com o fundamento de que exceção à regra da imunidade não inclui delitos resultantes de conflitos 
armados, conforme o disposto na Convenção Europeia sobre a Imunidade de Jurisdição dos Estados.

Tentou-se, também, proteger os direitos humanos no julgado Ferrini vs República Federal da Alemanha. Nesse caso, coube à Suprema Corte reformar a decisão inicial e negar a imunidade de jurisdição à Alemanha com fundamento no fato de que a imunidade não pode abranger atos que constituem crimes internacionais. A decisão foi um avanço diante de tantos julgados em que se nega a indenização e se privilegia a imunidade em face de atos que configuram crimes internacionais. O entendimento da Suprema Corte, no entanto, foi alterado na Corte Internacional de Justiça que decidiu a favor da concessão de imunidade de jurisdição ao Estado alemão.

Nota-se que, apesar dos esforços de algumas cortes em primar pela proteção aos direitos humanos, o que prevalece, em última instância, é a política das boas relações entre os Estados. Mitigam-se direitos fundamentais e cruciais para o desenvolvimento humano em prol de uma imunidade irrestrita.

O preceito basilar da responsabilidade civil afirma que, quando há um dano, ele deve ser indenizado. Essa regra deve ser aplicada de forma efetiva a fim de se evitarem maiores prejuízos às normas protetivas de direitos humanos. A impunidade desenfreada com base na imunidade de jurisdição, de certa forma, acaba por não limitar a prática de atos vis contra os direitos humanos. Assim, torturas, agressões e abusos poderão ser cometidos de forma irrestrita, já que não haverá punição.

Em relação à proteção dos direitos humanos sociais, a tutela se desenvolve no âmbito da imunidade de execução. Nesse aspecto, a jurisprudência fornece arcabouço para que a defesa dos direitos humanos sociais ocorre de forma mais eficaz. O que se protege, no contexto executório, são os bens afetos às atividades diplomáticas. Essa proteção encontra respaldo nas Convenções de Viena sobre Relações Diplomáticas de 1961 e sobre Relações Consulares de 1963.

Quando há um débito a ser quitado pelo Estado acreditante (normalmente de origem trabalhista), esse ente estatal saldará a dívida com seus bens que não estiverem vinculados às atividades de seus órgãos oficiais. É nesse sentido que decidiram as cortes superiores nos casos Genny vs República da Alemanha, Rosa Marinho Rocha vs Reino da Espanha, Edvaldo de Azevêdo vs Estado da Finlândia, Nestor Aquino vs embaixada dos Estados Unidos da América e Patrícia Gutierrez vs Consulado Geral do Chile em São Paulo.

O que se percebe, no entanto, é que, não comprovado que o bem disponível para quitar o débito não está afeto às atividades consulares e diplomáticas, o Estado estará desonerado de quitar as suas dívidas. Ressalta-se uma proteção ao bem patrimonial diante de falta de provas. Esse é o entendimento manifestado pelo Tribunal Superior do Trabalho nos casos narrados no capítulo anterior. Em todos os julgados colacionados, o TST entendeu que a execução contra o Estado estrangeiro era improcedente diante da impossibilidade de se distinguir se os valores depositados em conta corrente do país alienígena estavam afetados às funções precípuas da missão diplomática.

Percebe-se, assim, que os direitos humanos sociais, quando atrelados à seara trabalhista, gozam de uma proteção mais prática e efetiva do que direitos humanos violados em face de atos de guerra ou conflitos armados. O Estado, quando possui um débito, é responsabilizado a pagar por ele, de forma que a imunidade de execução é relativizada de forma mais ampla do que a imunidade de jurisdição.

A problemática em relação à efetiva indenização do dano na imunidade de execução relaciona-se com a dificuldade da parte em provar que os valores penhorados em conta corrente do Estado estrangeiro estão vinculados, efetivamente, à administração e manutenção da embaixada.

O uso desmedido da imunidade de jurisdição acaba permitindo que atos de violação aos direitos humanos ocorram sem que haja uma efetiva punição para tanto. $O$ instituto da 
relativização da imunidade de execução, no entanto, permite que o dano seja reparado levando-se em consideração apenas o fato de os bens estarem afetos às atividades diplomáticas e consulares.

Dessa forma, percebe-se que a jurisprudência brasileira em relação às exceções à imunidade de execução permite maior proteção aos direitos humanos sociais. Tal imunidade sofre uma relativização que permite que o dano causado pelo ente público seja reparado em sua integralidade.

Nota-se, assim, que as cortes superiores do Brasil relativizam a imunidade de execução a fim de se garantir a reparação do dano sofrido. O mesmo não se pode dizer das cortes europeia e americana de direitos humanos, que são mais rígidas na aplicação da imunidade de jurisdição.

Deve-se, assim, fazer uma ponderação de valores entre os atos praticados pelos Estados e a proteção à dignidade da pessoa humana a fim de se repreender a tortura, os maus tratos e as demais práticas que releguem os direitos humanos à ineficiência.

\section{CONCLUSÃO}

Diante de todo o relatado, conclui-se que a proteção aos direitos humanos não ocorre de forma eficaz no âmbito internacional. A aplicação rígida da imunidade de jurisdição impossibilita o reparo aos danos sofridos pela sociedade. Por outro lado, a relativização da imunidade de execução pelas Cortes Superiores brasileiras permite a reparação integral, quando se trata de bens não afetos à atividade diplomática ou consular.

Em relação à imunidade de jurisdição, nota-se que a maioria dos casos em que se questiona a imunidade em face da proteção dos direitos humanos ocorreu em situações de guerra ou de conflitos armados. A doutrina que defende a natureza de tais situações como atos de império acaba por permitir que violações como as relatadas no trabalho continuem a existir visto que não se vislumbra qualquer punição pelos danos causados.

Ainda que haja diplomas que prevejam a inaplicabilidade da imunidade de jurisdição, nenhum deles é efetivo em tutelar a proteção dos direitos humanos quando se tem uma violação em território externo ao do Estado signatário do diploma. Sintetizando: a imunidade de jurisdição deixa de ser aplicada apenas quando o ato cometido pelo Estado acreditante for praticado dentro do território do Estado acreditado. Trata-se de uma limitação pífia, haja vista que, conforme demonstrado nos julgados colacionados no trabalho, grande parte dos atos violadores dos direitos humanos são praticados fora do território do Estado acreditado. Assim, não há que se falar em inaplicabilidade da imunidade de jurisdição.

A política da boa relação entre os Estados prevalece sobre a possiblidade de se reparar o dano sofrido pela sociedade. Privilegiam-se aspectos políticos sobre aspectos jurídicohumanitários. Essa atitude acaba permitindo que que violações aos direitos humanos ocorram já que não há uma punição pelos danos causados. Nem mesmo a justificativa de que os atos cometidos configuravam crime internacional foi suficiente para afastar a imunidade de jurisdição dos Estados.

A responsabilidade civil que prima pela indenização de um dano quando esse ocorrer não é aplicada quando se trata da imunidade de jurisdição.

Na seara da imunidade de jurisdição em relação às organizações internacionais, aplica-se a imunidade de forma absoluta fundamentando-se em seus atos constitutivos e em tratados internacionais. Há, no entanto, proteção aos direitos humanos sociais quando as partes se valem de mecanismos indicados pelo próprio organismo internacional.

No tocante à imunidade de execução, no entanto, há reparação, desde que os bens disponíveis para saldar a dívida não estejam afetos às atividades diplomáticas ou consulares.

A relativização da imunidade de execução promovida pelas cortes superiores brasileiras permite a proteção dos direitos humanos sociais. O mesmo não ocorre em relação à imunidade de 
jurisdição aplicada no direito internacional que tem sua teoria aplicada de forma mais ampla pelas cortes europeia e americana.

A problemática em relação à proteção dos direitos humanos sociais vincula-se com a dificuldade de a parte comprovar que o montante penhorado em conta corrente do Estado estrangeiro não está afeto às atividades diplomáticas/consulares. Em razão da ausência de prova concreta, o TST, em seus julgados, entende que pela impenhorabilidade do montante da conta corrente.

A impossibilidade de se ter o efetivo ressarcimento dos danos causados aos direitos humanos sociais está relacionada a uma questão de cunho processual, já que a parte não tem condições de provar, nos autos, a efetiva vinculação dos bens com as atividades da embaixada. No que tange ao aspecto doutrinário, no entanto, a proteção aos direitos humanos sociais ocorre de forma definida, haja visa que é possível a constrição de bens não afetos às atividades diplomáticas para fins de indenização.

A proteção aos direitos humanos sociais ocorre de forma mais satisfatória em relação à imunidade de execução, principalmente quando se trata de quitação de dívidas de origem trabalhista. Essa proteção é mais eficaz do que a prevista pela imunidade de jurisdição o que faz com que o direito do trabalho tenha maior efetividade executória.

O que se deve fazer, para que os direitos humanos gozem de reparação indenizatória tanto quanto gozam os direitos humanos é uma ponderação de valores a fim de se relativizar a teoria da imunidade de jurisdição. A ponderação deve conflitar os atos praticados pelos Estados (atos de guerra, crimes internacionais, conflitos armados, etc.) com a proteção à dignidade da pessoa humana. Dessa forma, poder-se-á repreender e punir de forma eficaz os atos de tortura, de maus tratos e demais práticas que releguem os direitos humanos à ineficiência. Poder-se-á, assim, fazer com que o os direitos humanos gozem da mesma proteção doutrinária-prática que os direitos humanos sociais.

\section{REFERÊNCIAS BIBLIOGRÁFICAS}

ABREU, Patrícia Maria Lara; RAPOSO, Rodrigo Otávio Bastos Silva. Imunidade de jurisdição do Estado e reparação civil pela prática de tortura: o caso Zahra Kazemi v. República Islâmica do Irã. Revista de Direito Internacional, Brasília, v. 11, n. 2, p. 412-434, 2014.

BRANT, Leonardo Nemer Caldeira Brant; BIAZATTI, Bruno de Oliveira. A imunidade de jurisdição dos estados face o processo de humanização do direito internacional. Disponível em: <https://www.academia.edu/22720739/A_imunidade_de_jurisdi\%C3\%A7\%C3\%A30_dos_Estad os_face_o_processo_de_Humaniza\%C3\%A7\%C3\%A3o_do_Direito_Internacional>. Acesso em: 21 de maio de 2017.

CANADÁ. Supreme Court of Canada. Estate of the Late Zahra (Ziba) Kazemi, et al. v. Islamic Republic of Iran, et al.: 2014 SCC 62. Available at: <http://scc-csc.lexum.com/scc-csc/scccsc/en/item/14384/ index.do>. Acesso em: 23 maio 2017.

CARVAlHO FILHO, José dos Santos. Manual de Direito Administrativo. 20a ed. Rio de Janeiro: Lumen Juris, 2008.

FERNANDES, Camila Vicenci. Violações aos direitos humanos e a imunidade de jurisdição do Estado estrangeiro: novas tendências jurisprudenciais em relação à proteção dos indivíduos. Revista de Estudos Jurídicos UNESP, Franca, SP, v. 14, nº 19, 2010. 
GUERRA, Sidney. A responsabilidade internacional do Estado e a Corte Interamericana de Direitos Humanos. Revista de Direito Brasileira, São Paulo, SP, v. 1, nº 1, jul./dez. 2011.

ICD. Internacional Crimes Database. Disponível em: <http://www.internationalcrimesdatabase.org/Case/1090/Ferrini-v-Germany/>. Acesso em: 27 maio 2017.

INTERNACIONAL COURT OF JUSTICE. Disponível em: <http://www.icjcij.org/docket/files/143/16897.pdf>. Acesso em: 27 maio 2017.

MORAES, Alexandre de. Direito Constitucional. $28^{a}$ ed. São Paulo: Atlas, 2012.

PADILHA, Elisângela; BERTONCINI, Carla. A dignidade da pessoa humana na teoria dos direitos fundamentais de Robert Alexy: uma análise sobre o seu caráter absoluto ou relativo na ordem jurídico-constitucional. Revista de Direito Brasileira, São Paulo, SP, v. 13, nº 6, jan./abr. 2016.

PEDEREIRA, Pinho. A concepção relativista das imunidades de jurisdição e execução do Estado estrangeiro. Revista de Informação Legislativa, Brasília, DF, a. 35, nº 140, out./dez. 1998.

PEREIRA, Antônio Celso Alves. As normas de jus cogens e os direitos humanos. Disponível em: <http://www.faa.edu.br/revistas/docs/RID/2009/RID_2009_02.pdf>. Acesso em 28 maio 2017.

PIOVESAN, Flávia. Direitos Humanos e o Direito Constitucional Internacional. 14 ed. São Paulo: Saraiva, 2013.

PORTELA, Paulo Henrique Gonçalves. Direito Internacional Público e Privado. $6^{\text {a }}$ ed. Salvador: Juspodium, 2014.

THEODORO JÚNIOR, Humberto. Curso de Direito Processual Civil. 47 a ed. Rio de Janeiro: Forense, 2007.

TRIBUNAL REGIONAL DO TRABALHO DA $18^{\mathrm{a}}$ REGIÃO. Disponível em: <http://www.trt18.jus.br/portal/bases-juridicas/jurisprudencia/jurisprudencia-tematica/1-7jurisdicao/1-estado-estrangeiro-imunidade/>. Acesso em 28 maio 2017

TORRES, Eneas Bazzo. A imunidade de jurisdição do estado estrangeiro e o problema da execução. Revista TST, Brasília, vol. 78, nº 1, 2012.

VILELA, Janaína Alcântara. Imunidade de jurisdição e imunidade de execução: uma visão trabalhista sobre o tema. Disponível em: <http://www.publicadireito.com.br/artigos/?cod=b8b9c74ac526fffb>. Acesso em 20 maio 2017.

WESTLAW. Disponível em: <http://www.iilj.org/wp-content/uploads/2016/08/FSIA-Princz-v.Germany.pdf>. Acesso em 21 maio 2017. 